\title{
A Research on Heat Exchangers used in Generation-IV Nuclear Reactors
}

\author{
Sagar Sharda a, Mehul Rathod a, Harshil Thakkar a, Utsav Vyas ${ }^{\mathrm{a}}$ \\ ${ }^{a}$ Research Scholar, \\ Gandhinagar Institue of Technology, Gandinagar, \\ Gujarat - 382721, India.
}

\begin{abstract}
Generating electricity with nuclear energy permits economic and social development to be sustainable; that is, not limited by encroaching environmental concerns. A nuclear power plant needs ergonomically sustainable and energy efficient equipments in its power systems as to provide clean and green energy. As we know, a heat exchanger plays a vital role in transferring heat from one working fluid to another as a heat surface phenomenon transition. Nuclear Energy is in the demand for energy efficient environmental surroundings and it is needed to be taken care of the production of this energy for better energy and power exploration. The nuclear reactors of tomorrow will offer a variety of benefits such as alternative fuel generation, process fuel, etc. Some designs will even allow us to recover and recycle elements in nuclear waste that can still produce energy.

These ADVANCED REACTORS i.e. Generation III reactors work at high operating pressure and temperature and thus they are required to remove excess heat to achieve minimum pressure drop and attain high mechanical efficiency of the reactors.[1] This can be achieved by installation of heat exchangers as a boost to the power system which has to withstand high pressure and temperature of working fluids dealing with it. The design is also based on constraints such as Compactness and thus it can be achieved by designing a Compact heat exchanger for the operating system. Mechanical rigidity also plays an important role when a system operates at high pressure and temperature conditions. Thus, taking this factor into consideration, diffusion bonding technique is used to eliminate the factors affecting the mechanical strength and rigidity of the heat exchanger operating at high pressure and temperature, so that the objectives can be achieved. Here, the thermo-hydraulic performance of compact heat exchanger with various considerations taken into account for Advanced Nuclear Power Systems is studied and analyzed for clean energy production and obtaining higher efficiency of the power system.

Diffusion bonded compact heat exchanger provides a tough bondage to the stack of plates stacked on each other to withstand the high pressure distribution of the fluids through header and flow pipes and thus, to maintain the required temperature of the fluid to carry out the required heat transfer phenomenon. Thus here, in this research paper,the thermo-hydraulic performance of compact heat exchanger with various considerations taken into account for Advanced Nuclear Power Systems is studied and analyzed for clean energy production and obtaining higher efficiency of the power system.
\end{abstract}

Fig.1 Etched micro-channel flow path

\section{LIST OF FIGURES:}

Fig. 2 Flow path of hot and cold channel

Fig.3 3D view model of Diffusion bonded Compact Heat Exchanger (DCHE)

Fig.4 Top view and heat transfer

Fig.5 Layout of DCHE model

Fig.6 (a) TV (b) LHSV (c) RHSV

Fig.7 Solidworks drawing of hot fluid side

Fig. 8 Hot fluid plate

Fig.9 Solidworks drawing of cold fluid side

Fig.10 Cold fluid plate

Fig.11 Zig-zag geometry

Fig.12 Model of flow channels

Fig.13 Liquid Helium inlet micro-channel

Fig.14 Liquid helium outlet micro-channel

Fig. 15 s-CO2 inlet micro-channel

Fig.16 s-CO2 outlet micro-channel

Fig.17 Temperature distribution on plates

Fig.18 Temperature distribution on LHe plates

Fig.19 Temperature distribution on s-CO2 plates

Fig.20 All domains temperature distribution on all plates

Fig.21 Pressure distribution in s-CO2 hot plates

Fig. 22 Pressure distribution in LHe cold plates

Fig.23 All domains pressure distribution

Fig.24 Pressure v/s Temperature graph on LHe cold plate side

Fig.25 Pressure v/s Temperature graph on s-CO2 hot plate side 
Table 1 - Summary of specification of prototypic PCHE design

LIST OF TABLES:

Table 2 - Summary of zig zag micro-channel specification

Table 3 - Summary of thermal hydraulic performance of prototypic PCHE design

Table 4 - Mesh Report of working fluids

Table 5 - Domain physics of working fluids

Table 6 - Boundary physics of working fluids

\section{INTRODUCTION}

Nuclear energy being an essential source of energy plays vital role at global level and thus it becomes invariably important to use equipment of maximum possible efficiency in nuclear power plants to generate power. Heat exchanger being a vital component plays a huge role in nuclear power generation so it is very essential to use heat exchangers of updated technology and concepts at nuclear power plants.

Printed circuit micro-channels heat exchanger (PCHEs) are the primary compact heat exchangers of interest. This research paper is an attempt to replace IHX (Intermediate Heat Exchanger) with diffusion bonded compact heat exchanger withstanding high pressures and temperatures reducing the operational and design cost of the power system.

\section{Printed Circuit Heat Exchangers (PCHE):}

A Printed Circuit Heat Exchanger (PCHE) is recognized as a plate-fin type heat exchanger. PCHE is dependent primarily on the two technologies of chemical etching and diffusion bonding. First, flow channels are etched chemically on the metal plates. Then they are stacked to produce one block by diffusion bonding. It is a compact heat exchanger. Among several methods used to increase the heat transfer rate in compact heat exchangers, PCHE uses method of disturbing the boundary layers of solid surface and interchange them using fluid from core.This way it creates new boundary layer which has improved temperature gradient.

\section{PCHE Construction:}

They are made from flat metal plates into which fluid flow channels are chemically etched. The technique is similar to that used for etching electrical printed circuits so it is capable of creating fluid circuits of numerous types and complexity.

The design of channels on plates for each fluid is dependent on temperature and pressure-drop of heat exchange. After considering these factors, when an optimal thermal design has been developed for an exchanger, the artwork required for plate manufacturing is rapidly and easily gets generated from computer.

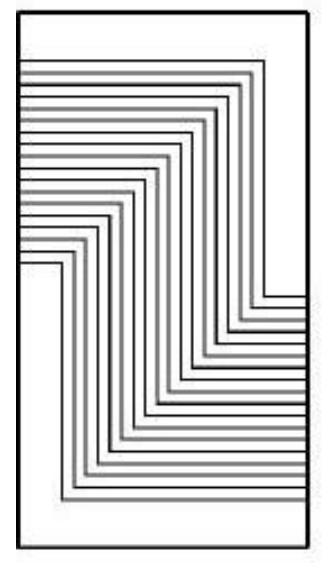

Fig.1 Etched micro-channel flow path [2]
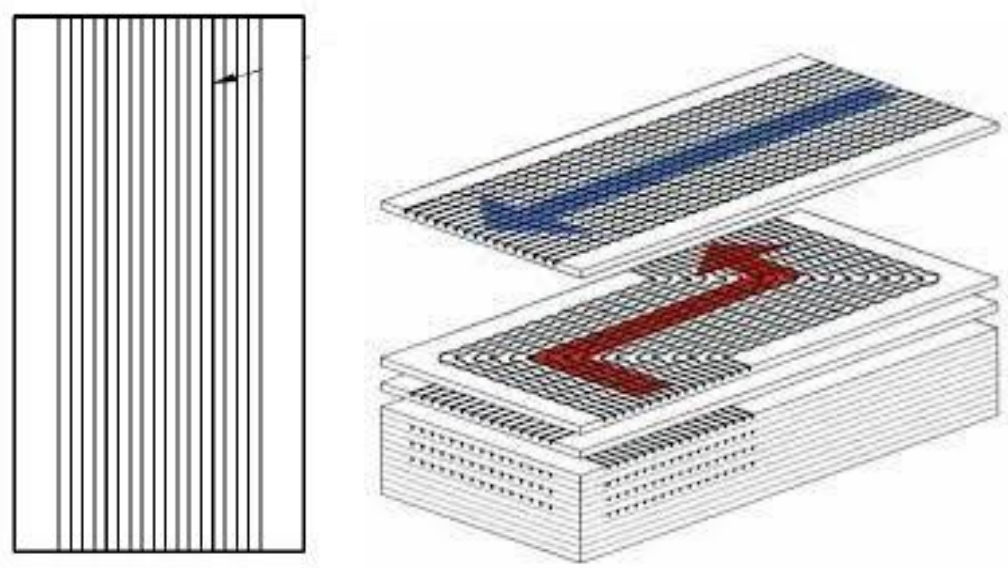

Fig.2 Flow path of hot and cold channel [2]

As PCHE have complex geometry, it is not convenient to generate it using conventional welding techniques as it will produce residual stress. To avoid such limitations, a solid-state welding process known as the diffusion bonding technique has become an attractive option for the PCHE fabrication.

Diffusion bonding is defined as "a method for joining comprising the steps of closely sticking base materials together and pressing these materials against each other at a temperature not exceeding their melting points, while suppressing their plastic deformation to a minimum, so as to cause the diffusion of atoms at the joining interface to complete the bonding."

Thus produced Diffusion-bonded Compact Heat Exchanger (DCHE) is a compact heat exchanger with improved heat transfer performance and high pressure resistance. In a DCHE, several hundreds of plates are stacked, each with flow passages. Significant features are the flow passage size and joining. 


\section{Material selection study:}

It is necessary to make PCHE robust so that it can withstand possible failure caused by creep, burst, fatigue, and creep-fatigue loading when it is operating at high temperature.The primary step of the design phase is to identify material with excellent diffusion bonding properties and also few mechanical properties for an efficient fabrication of the PCHE.

In this study, the material Alloy $800 \mathrm{H}$ is selected for the diffusion bonded PCHE fabrication due to its applicability in the nuclear power plants operating in high temperature range. Alloy $800 \mathrm{H}$ is an iron-based super alloy qualified by the ASME Section III Division 5 Code for use in the nuclear power plants operating at temperatures up to $760 \mathrm{C}$ and a service life of about 35 years [3]. Hence, in this study, the Alloy $800 \mathrm{H}$ is selected for the diffusion bonding and the mechanical performance evaluations.

\section{MECHANICAL DESIGN OF PCHE:}

3D modelling and dimensioning in SOLIDWORKS software

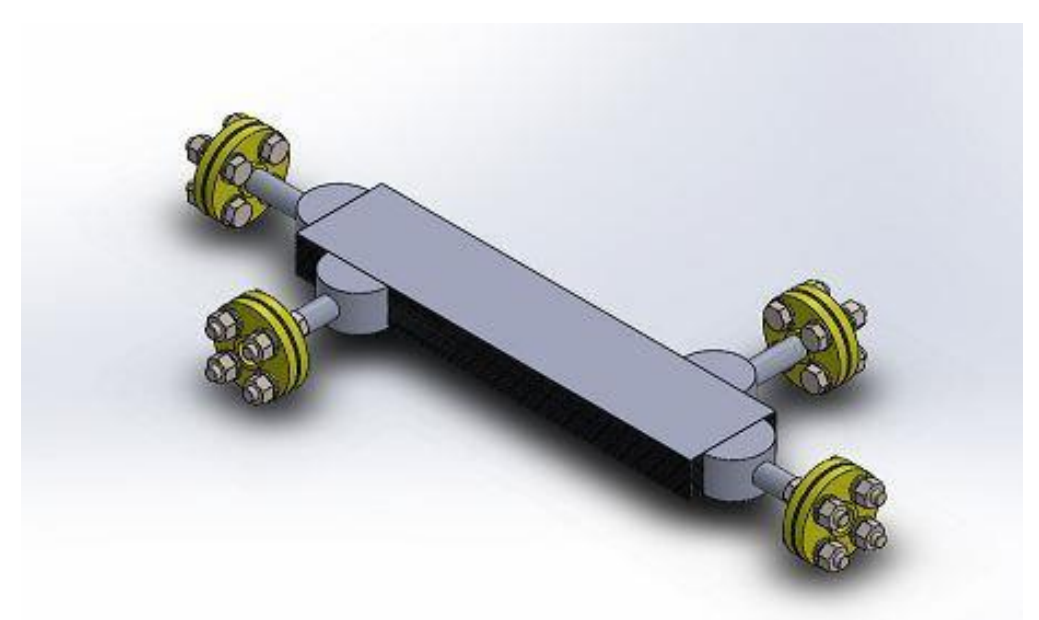

Fig.3 3D view model of Diffusion bonded Compact Heat Exchanger (DCHE)

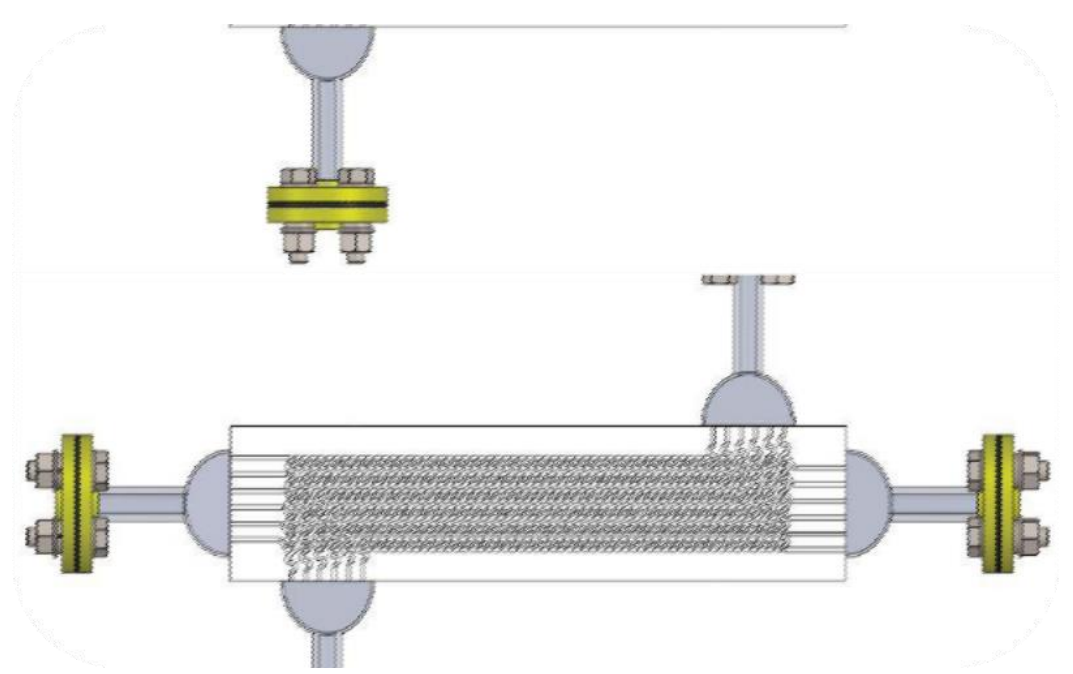

Fig.4 Top view and heat transfer phenomenon of DCHE 

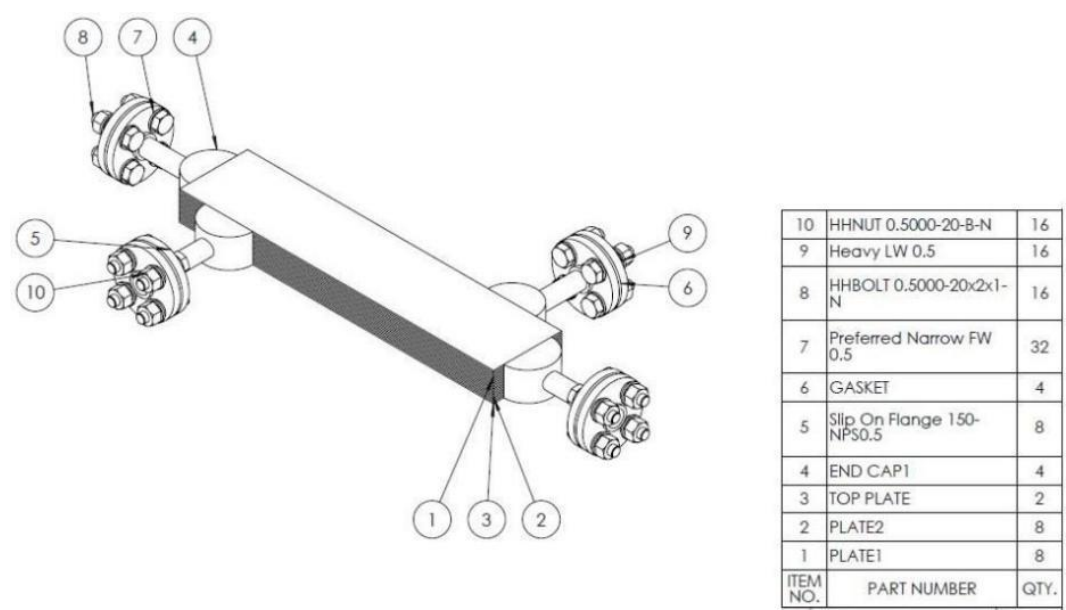

Fig.5 Layout of DCHE model

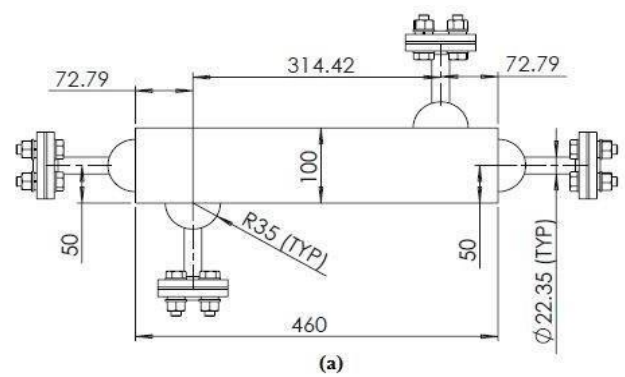

ALL DIMESNIONS ARE IN MM
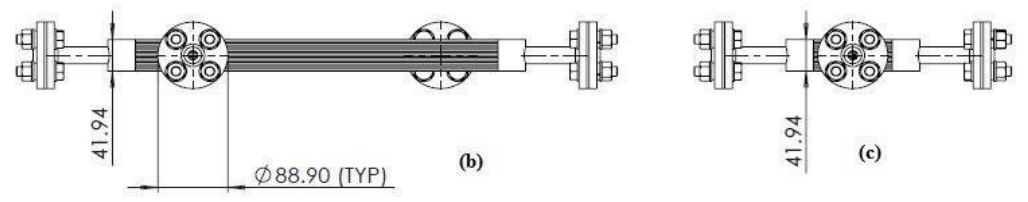

Fig.6 (a) TV (b) LHSV (c) RHSV

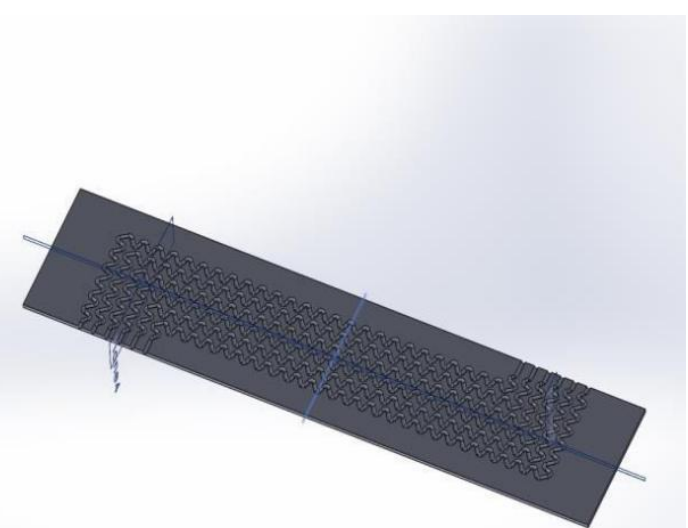

Fig.7 Solidworks drawing of hot fluid side

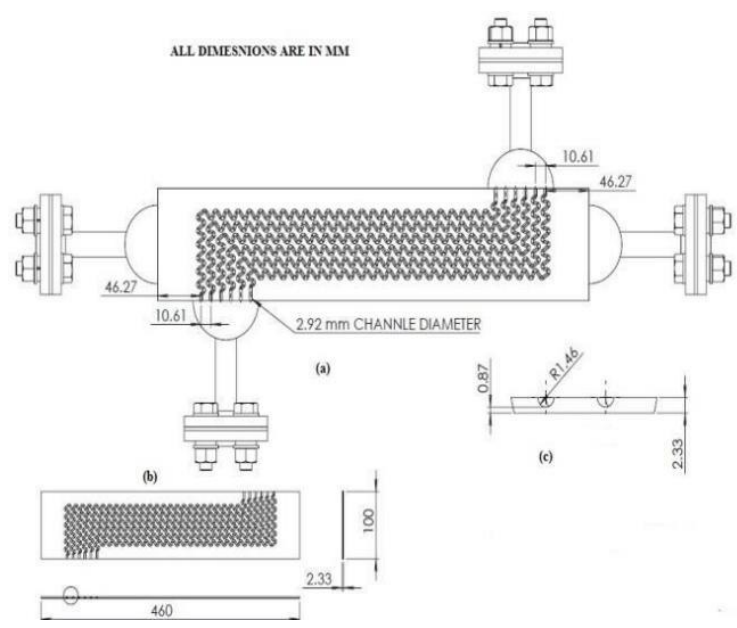

Fig.8 Hot fluid plate 


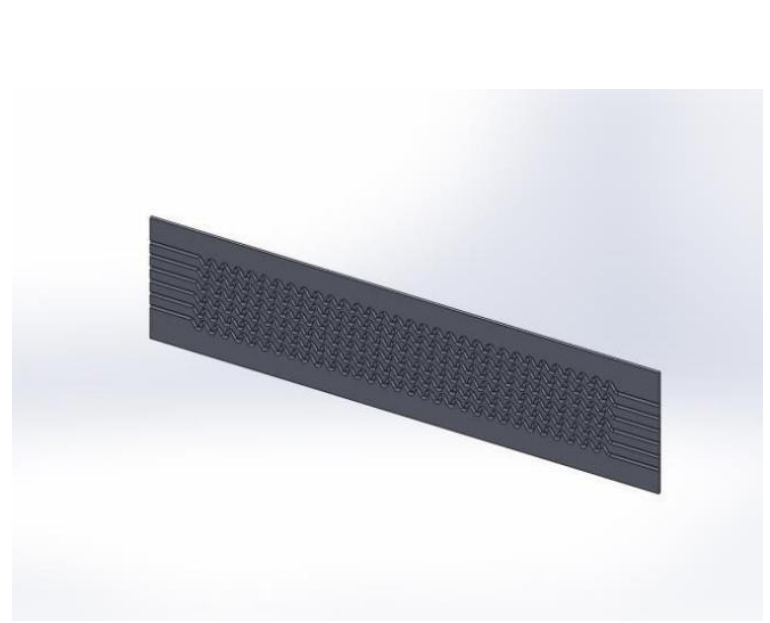

Fig.9 Solidworks drawing of cold fluid side

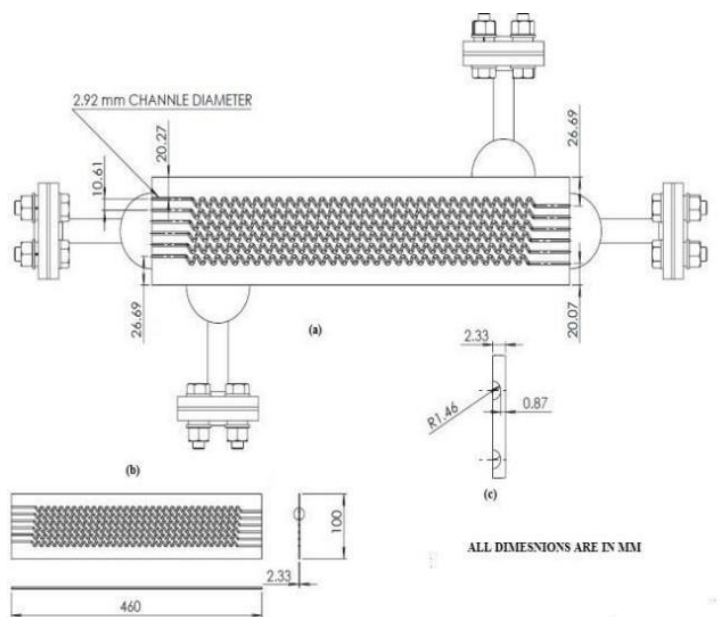

Fig.10 Cold fluid plate

\section{Specifications of Prototypic PCHE Design:}

The plate (or shim) design of the test PCHE that is given below is tested in the STL.It is based on the scaled-down test design. The thermal design is determined according to the scaling analysis of the prototypic optimized design.

Table 1 - Summary of specification of prototypic PCHE design:

\begin{tabular}{|c|c|c|c|c|c|c|}
\hline \multicolumn{2}{|c|}{ CATEGORY } & SR. NO. & ITEM & UNITS & TEST & PROTOTYPE \\
\hline \multirow{13}{*}{$\begin{array}{c}\text { GEOMETRIC } \\
\text { DATA }\end{array}$} & \multirow{5}{*}{ General } & 1 & $\begin{array}{c}\text { Heat exchanger } \\
\text { core volume }\end{array}$ & M3 & $\begin{array}{c}6.27 * 10 \\
\wedge-4\end{array}$ & 0.166 \\
\hline & & 2 & $\begin{array}{c}\text { Heat exchanger } \\
\text { mass }\end{array}$ & $\mathrm{Kg}$ & $\begin{array}{c}5.24 * 10 \\
\wedge-3\end{array}$ & 1.39 \\
\hline & & 3 & Frontal area & M2 & $\begin{array}{c}1.36 * 10 \\
\wedge-3\end{array}$ & 36 \\
\hline & & 4 & $\begin{array}{l}\text { Number of plates } \\
\text { per block }\end{array}$ & - & 16 & 312 \\
\hline & & 5 & $\begin{array}{c}\text { Heat exchanger } \\
\text { physical } \\
\text { length }\end{array}$ & $\mathrm{M}$ & 0.46 & 0.46 \\
\hline & \multirow{8}{*}{ Primary side } & 6 & Channel diameter & $\mathrm{Mm}$ & 2.92 & 2.92 \\
\hline & & 7 & $\begin{array}{l}\text { Hydraulic } \\
\text { diameter }\end{array}$ & $\mathrm{Mm}$ & 1.78 & 1.78 \\
\hline & & 8 & Channel angle & Deg & 19.29 & 19.29 \\
\hline & & 9 & $\begin{array}{c}\text { Longitudinal } \\
\text { pitch }\end{array}$ & $\mathrm{Mm}$ & 34.41 & 34.41 \\
\hline & & 10 & Transverse pitch & $\mathrm{Mm}$ & 4.18 & 4.18 \\
\hline & & 11 & Plate thickness & $\mathrm{Mm}$ & 2.33 & 2.33 \\
\hline & & 12 & $\begin{array}{r}\text { Number of } \\
\text { channels per } \\
\text { plates }\end{array}$ & - & 8 & 141 \\
\hline & & 13 & Flow area & M2 & $\begin{array}{c}2.14 * 10 \\
\wedge-4\end{array}$ & 7.35 \\
\hline & \multirow{7}{*}{$\begin{array}{l}\text { Secondary } \\
\text { side }\end{array}$} & 14 & $\begin{array}{r}\text { Hydraulic } \\
\text { diameter }\end{array}$ & $\mathrm{Mm}$ & 1.13 & 1.13 \\
\hline & & 15 & Fin angle & Deg & 52 & 52 \\
\hline & & 16 & $\begin{array}{c}\text { Longitudinal } \\
\text { pitch }\end{array}$ & $\mathrm{mm}$ & 7.57 & 7.57 \\
\hline & & 17 & Transverse pitch & $\mathrm{Mm}$ & 3.43 & 3.43 \\
\hline & & 18 & Plate thickness & $\mathrm{Mm}$ & 1.5 & 1.5 \\
\hline & & 19 & $\begin{array}{r}\text { Number of } \\
\text { channels per } \\
\text { plates } \\
\end{array}$ & - & 10 & 173 \\
\hline & & 20 & Flow area & M2 & $\begin{array}{c}1.32 * 10 \\
\wedge-4\end{array}$ & 4.46 \\
\hline
\end{tabular}




\section{Zig-zag micro-channels geometry surface design:}

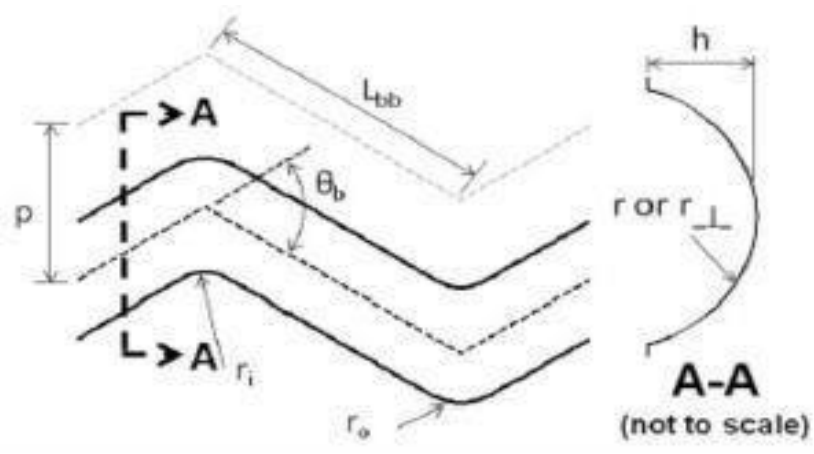

Fig.11 Zig-zag geometry [1]

Table 2 Summary of zig zag micro-channel specification [1]

\begin{tabular}{|c|c|c|c|}
\hline Description & Symbol & Unit & Design value \\
\hline Bend to bend length & $\mathrm{L}_{\mathrm{bb}}$ & $\mathrm{mm}$ & 4.724 \\
\hline Bend angle & $\theta_{\mathrm{b}}$ & $\mathrm{deg}$ & 52 \\
\hline Inner bend radius & $\mathrm{r}_{\mathrm{i}}$ & $\mathrm{mm}$ & 0.583 \\
\hline Outer bend radius & $\mathrm{r}_{\mathrm{o}}$ & 0.876 \\
\hline Lateral pitch & $\mathrm{p}$ & $\mathrm{mm}$ & 3.277 \\
\hline Fillet radius & $\mathrm{r}$ & $\mathrm{mm}$ & 0.95 \\
\hline Channel depth & $\mathrm{d}$ & $\mathrm{mm}$ & 0.95 \\
\hline Hydraulic radius & $\mathrm{D}_{\mathrm{h}}$ & 1.013 \\
\hline
\end{tabular}

Table 3 - Summary of thermal hydraulic performance of prototypic PCHE design

\begin{tabular}{|c|c|c|c|c|c|c|}
\hline \multicolumn{2}{|c|}{ CATEGORY } & SR. & ITEM & UNITS & TEST & PROTOTYPE \\
\hline \multirow{6}{*}{ INPUT DATA } & \multirow{3}{*}{$\begin{array}{c}\text { PRIMARY } \\
\text { SIDE }\end{array}$} & 1 & Mass flow rate & $\mathrm{Kg} / \mathrm{s}$ & 0.0125 & 428 \\
\hline & & 2 & Pressure & $\mathrm{MPa}$ & 2 & 7 \\
\hline & & 3 & Inlet temp. & Deg C & 745 & 800 \\
\hline & \multirow{3}{*}{ SECONDARY SIDE } & 4 & Mass flow rate & $\mathrm{Kg} / \mathrm{s}$ & 0.0885 & 2991 \\
\hline & & 5 & Pressure & $\mathrm{MPa}$ & 16 & 20 \\
\hline & & 6 & Inlet temp. & Deg C & 433.8 & 488.8 \\
\hline \multirow{10}{*}{$\begin{array}{l}\text { THERMO - } \\
\text { HYDRAULIC } \\
\text { DATA }\end{array}$} & \multirow{5}{*}{$\begin{array}{c}\text { PRIMARY } \\
\text { SIDE }\end{array}$} & 7 & Outlet temp. & Deg C & 449.7 & 504.4 \\
\hline & & 8 & Reynolds no. & - & 2484 & 2372 \\
\hline & & 9 & Pressure drop & $\mathrm{kPa}$ & 31.51 & 14.66 \\
\hline & & 10 & $\begin{array}{c}\text { Heat transfer } \\
\text { coefficient }\end{array}$ & $\begin{array}{r}\mathrm{kW} / \mathrm{m} 2 \\
\operatorname{deg} \mathrm{C}\end{array}$ & 2.64 & 2.70 \\
\hline & & 11 & $\begin{array}{l}\text { Heat transfer } \\
\text { area }\end{array}$ & $\mathrm{m} 2$ & $\begin{array}{c}2.35 * 10 \\
\wedge-1\end{array}$ & 80.76 \\
\hline & \multirow{5}{*}{ SECONDARY SIDE } & 12 & Outlet temp. & Deg C & 610.8 & 665.1 \\
\hline & & 13 & Reynolds no. & - & 28576 & 19828 \\
\hline & & 14 & Pressure drop & $\mathrm{kPa}$ & 48.80 & 48.20 \\
\hline & & 15 & $\begin{array}{c}\text { Heat transfer } \\
\text { coefficient }\end{array}$ & $\begin{array}{r}\mathrm{kW} / \mathrm{m} 2 \\
\operatorname{deg} \mathrm{C}\end{array}$ & 3.10 & 3.08 \\
\hline & & 16 & $\begin{array}{c}\text { Heat transfer } \\
\text { area }\end{array}$ & M2 & $\begin{array}{c}2.88 * 10 \\
\wedge-1\end{array}$ & 97.13 \\
\hline \multirow{2}{*}{\multicolumn{2}{|c|}{ AUXILIARY DATA }} & 17 & $\begin{array}{c}\text { Heat exchanger } \\
\text { capacity }\end{array}$ & $\mathrm{kW}$ & 19.2 & $6.57 * 10^{\wedge} 3$ \\
\hline & & 18 & Effectiveness & $\%$ & 71.28 & 72.47 \\
\hline
\end{tabular}

ANALYTICAL RESULTS:

\section{ANSYS FLUENT Report}

Table 4 Mesh Report of working fluids

\begin{tabular}{|l|l|l|}
\hline Domain & Nodes & Elements \\
\hline Cold fluid - LHe domain & 278393 & 187175 \\
\hline Hot fluid - s-CO2 domain & 373157 & 186918 \\
\hline Plates & 1898856 & 10099090 \\
\hline All domains & 2450406 & 10473183 \\
\hline
\end{tabular}




\section{Physics Report}

Table 5 - Domain physics of working fluids

\begin{tabular}{|c|cc|}
\hline \multicolumn{3}{|c|}{ Domain - Liquid Helium cold domain } \\
\hline Type & \multicolumn{1}{|c|}{ Cell } \\
\hline Domain - supercritical carbon dioxide hot domain \\
\hline Type & \\
\hline & Cell \\
\hline Type & Domain - Plates \\
\hline
\end{tabular}

Table 6- Boundary physics of working fluids

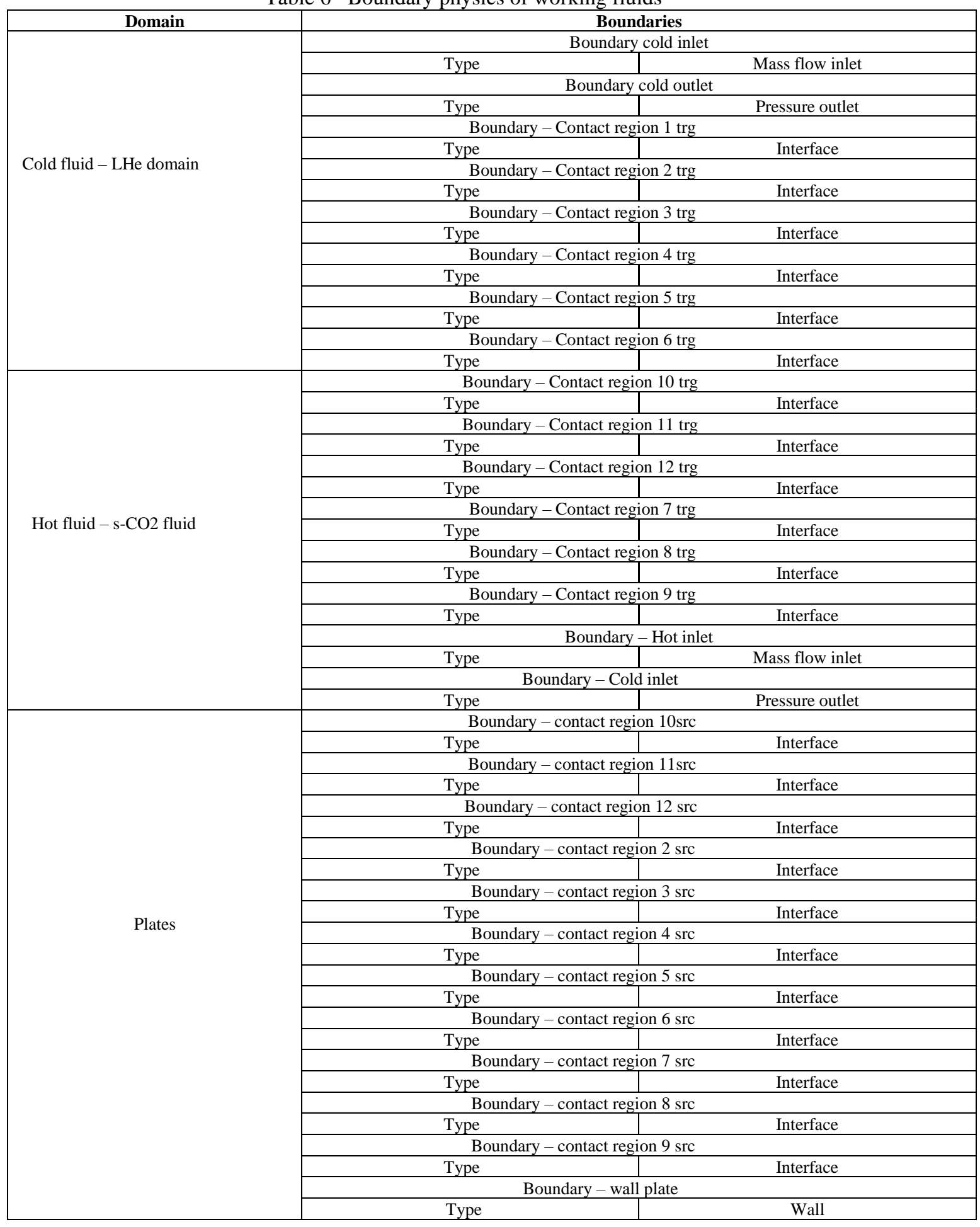




\section{User data:}

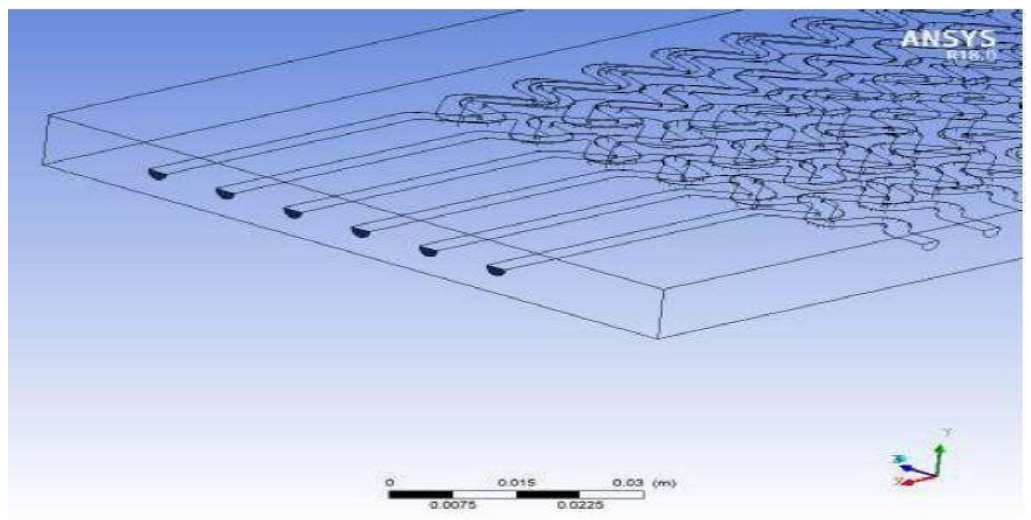

Fig.12 Model of flow channels

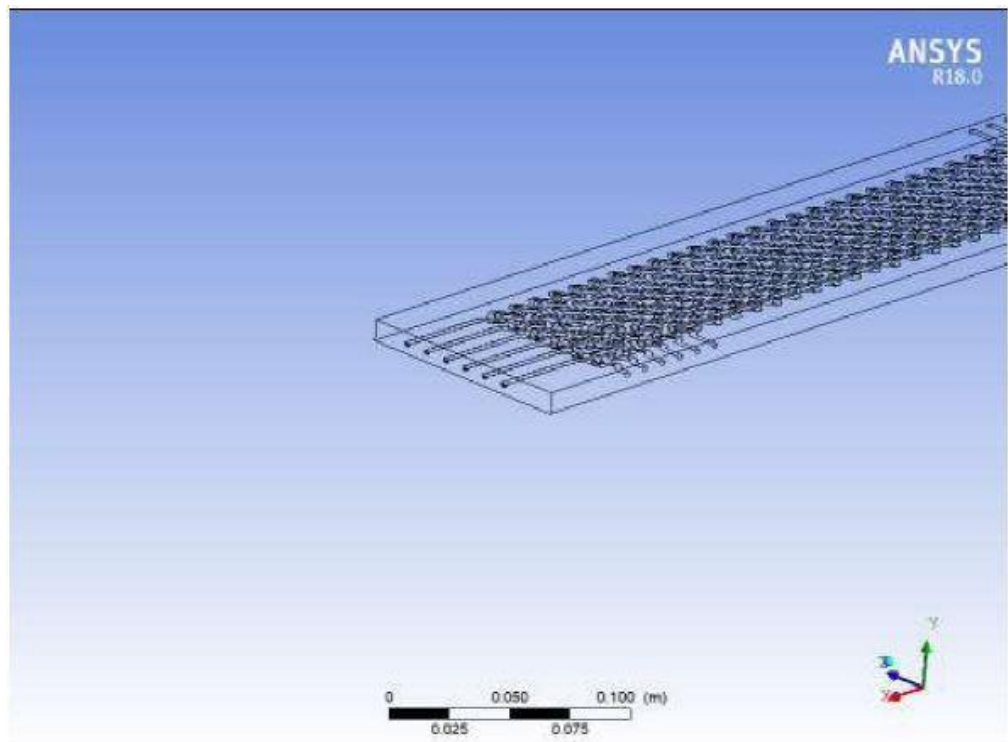

Fig.13 Liquid Helium inlet micro-channel

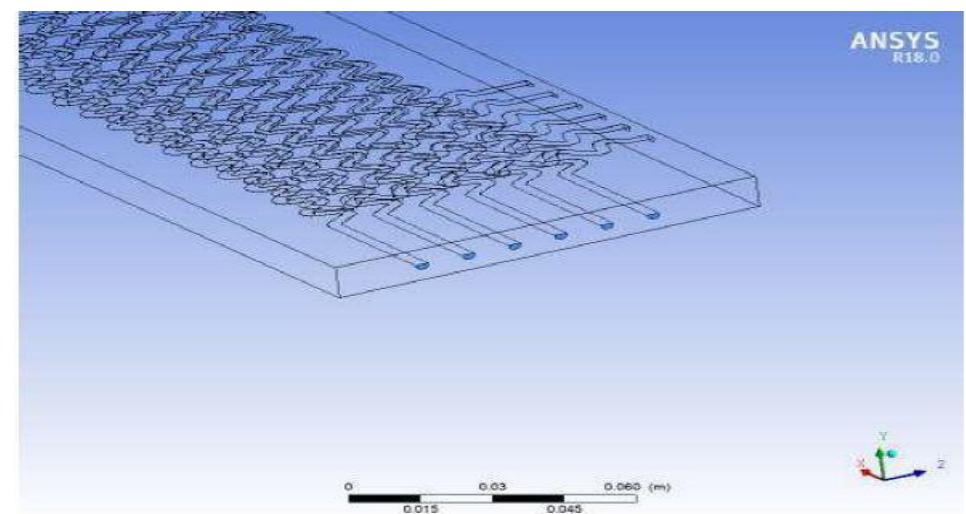

Fig.14 Liquid helium outlet micro-channel 


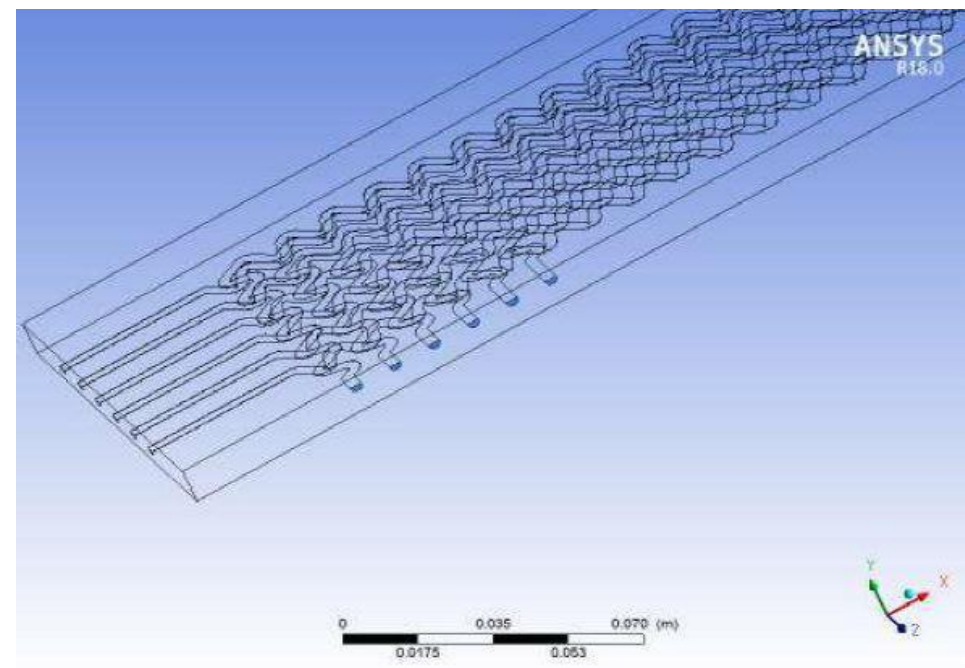

Fig.15 S-CO2 inlet micro-channel

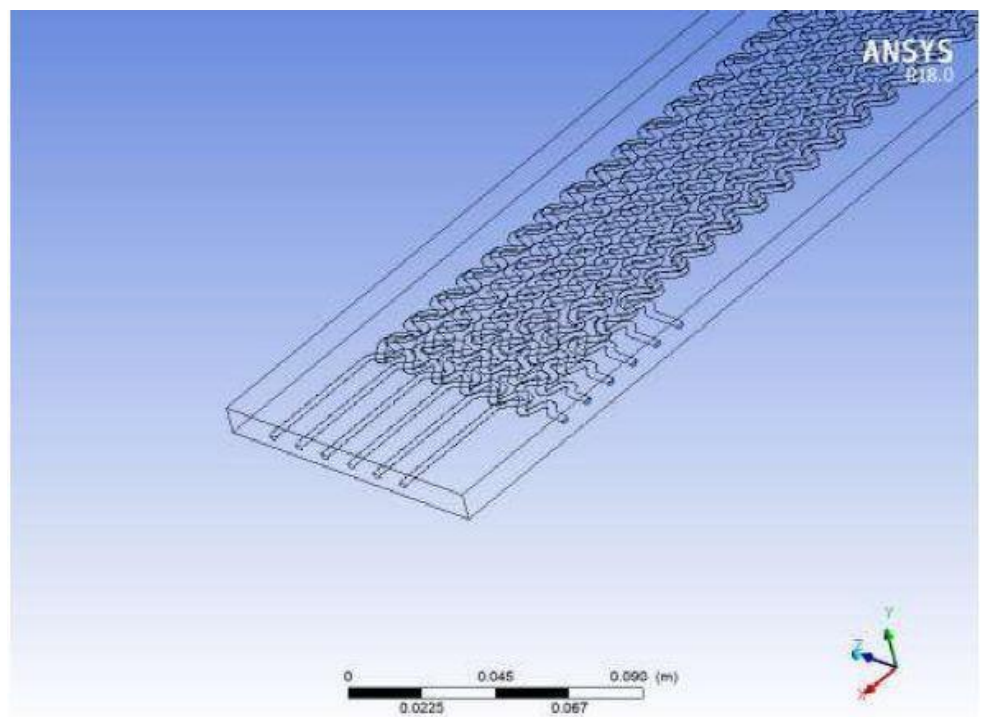

Fig.16 s-CO2 outlet micro-channel

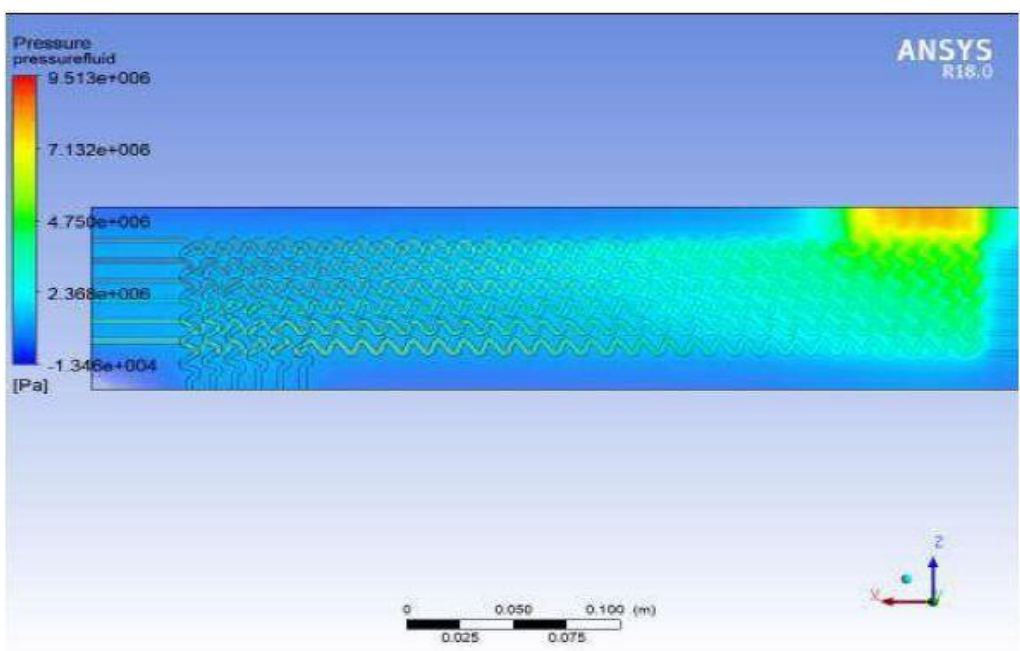

Fig.17 Temperature distribution on plates 


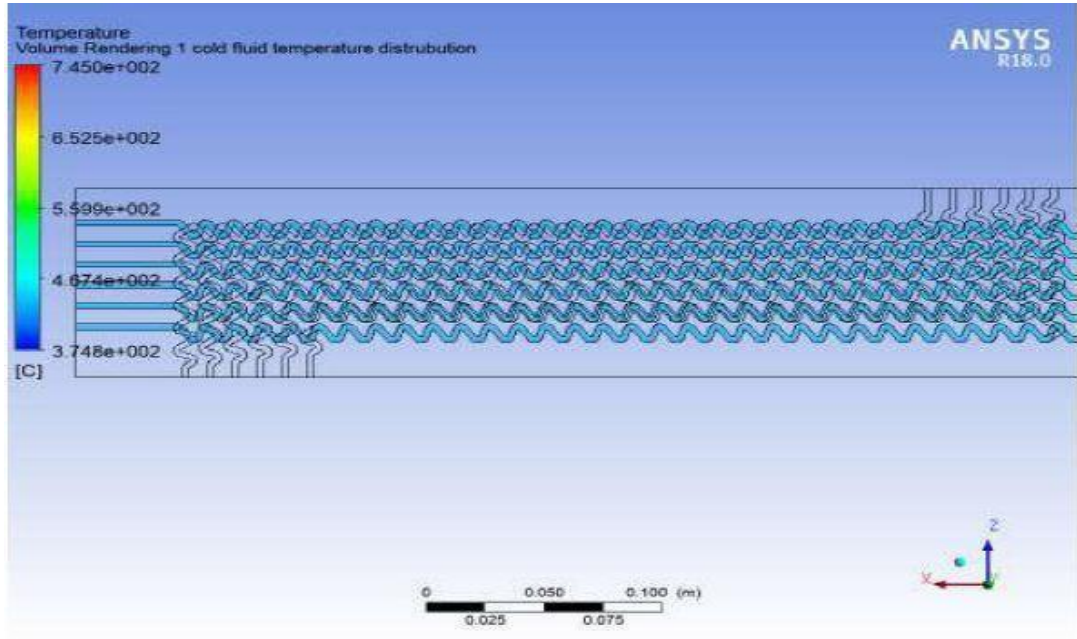

Fig.18 Temperature distribution on LHe plates

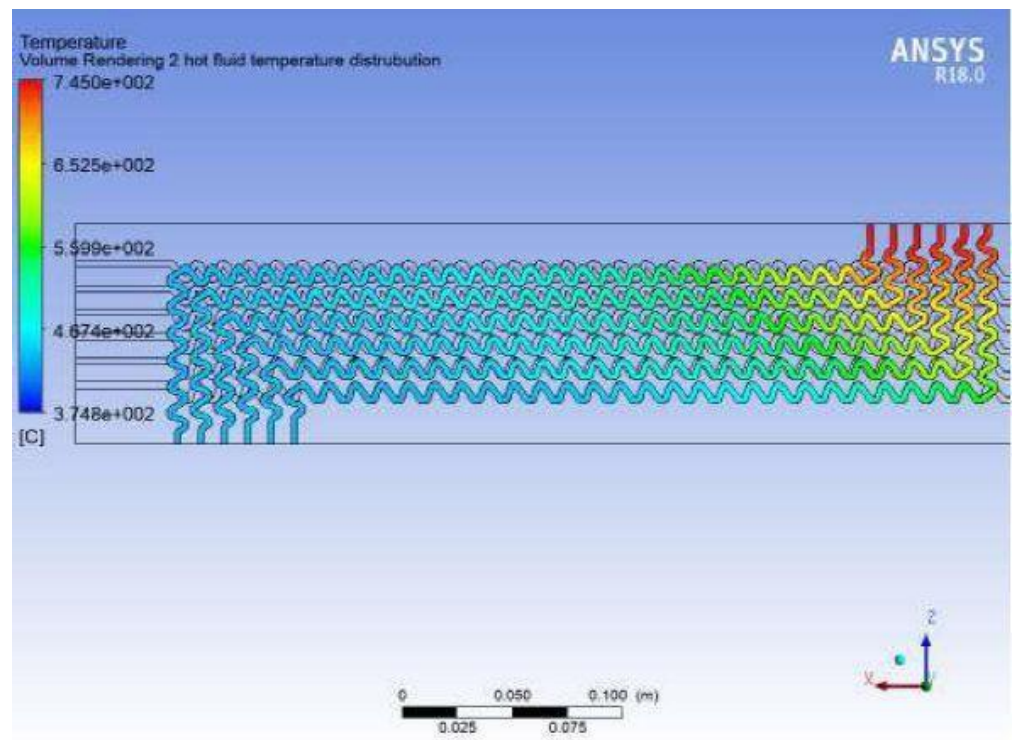

Fig.19 Temperature distribution on s-CO2 plates

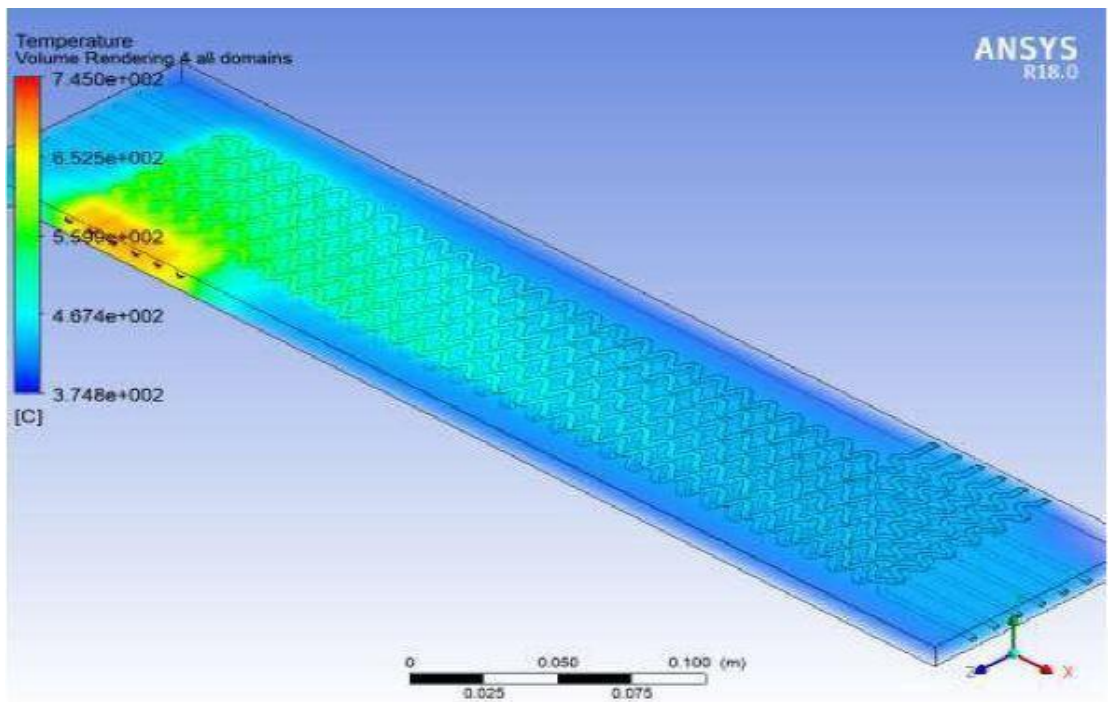

Fig.20 All domains temperature distribution on all plates. 


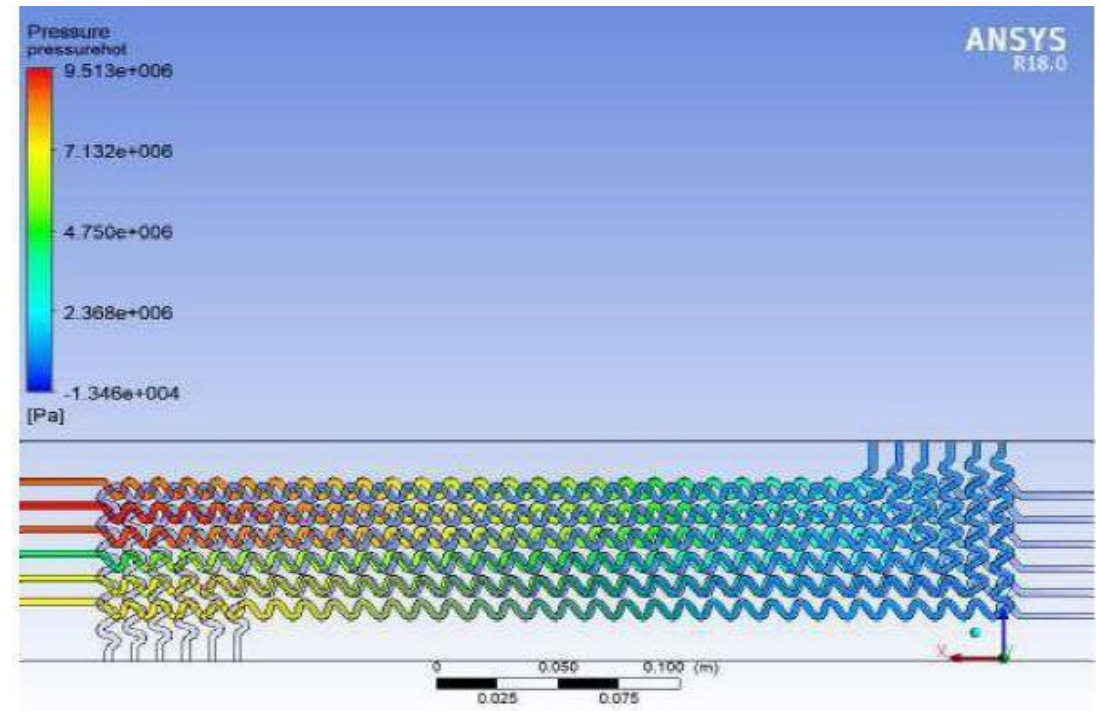

Fig.21 Pressure distribution in s-CO2 hot plates.

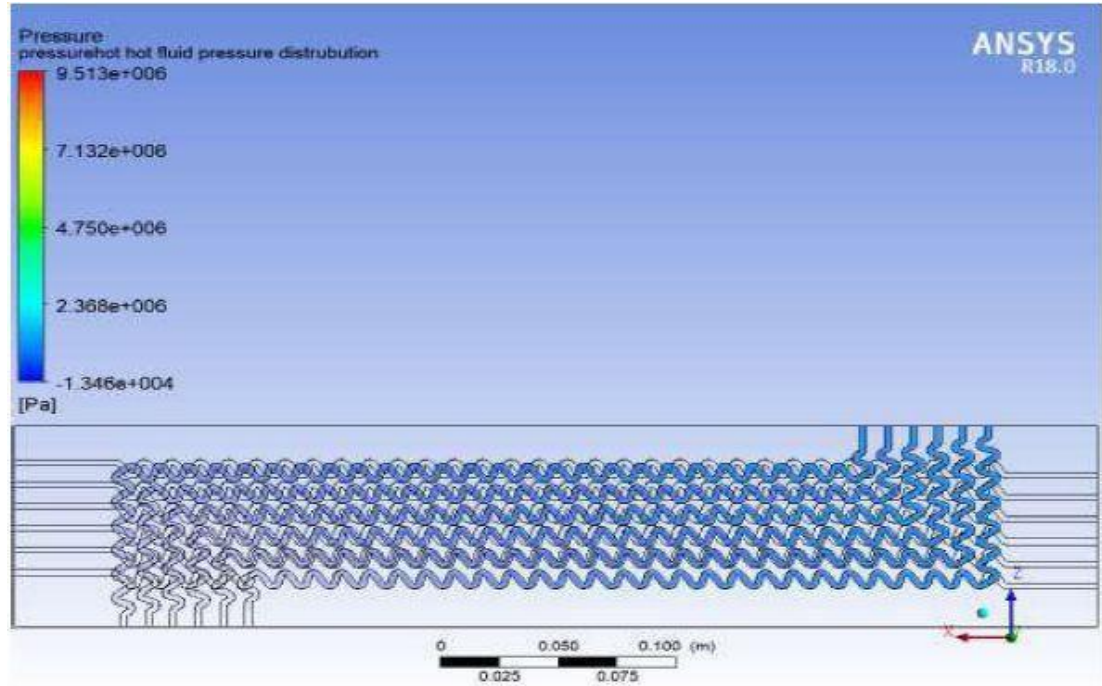

Fig.22 Pressure distribution in LHe cold plates.

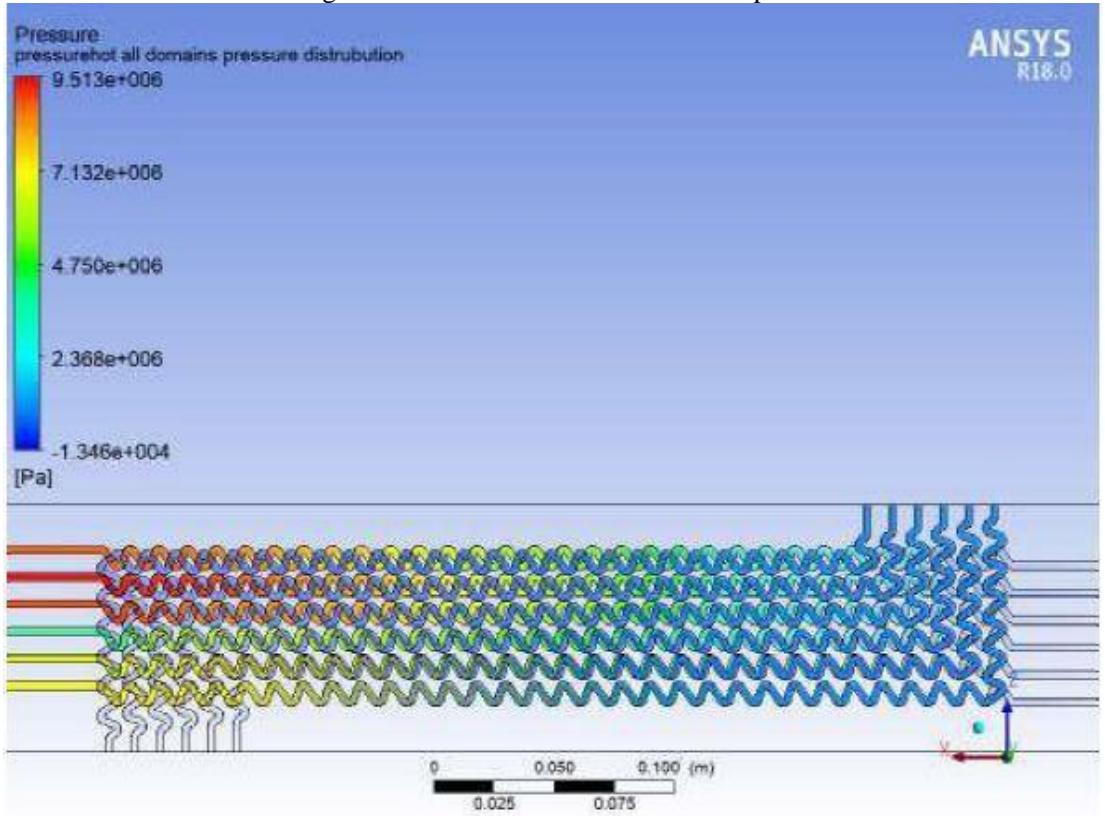

Fig.23 All domains pressure distribution 


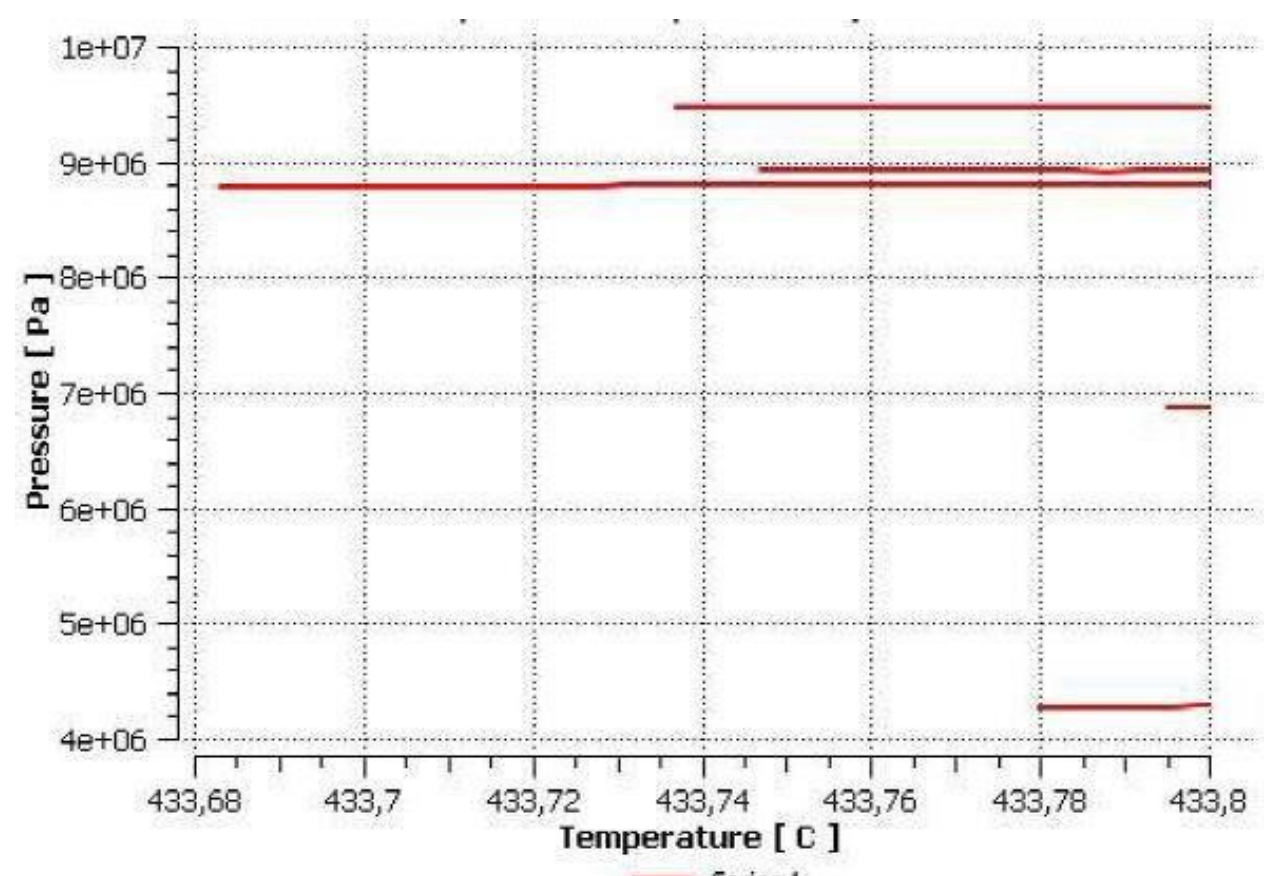

Fig.24 Pressure v/s Temperature graph on LHe cold plate side

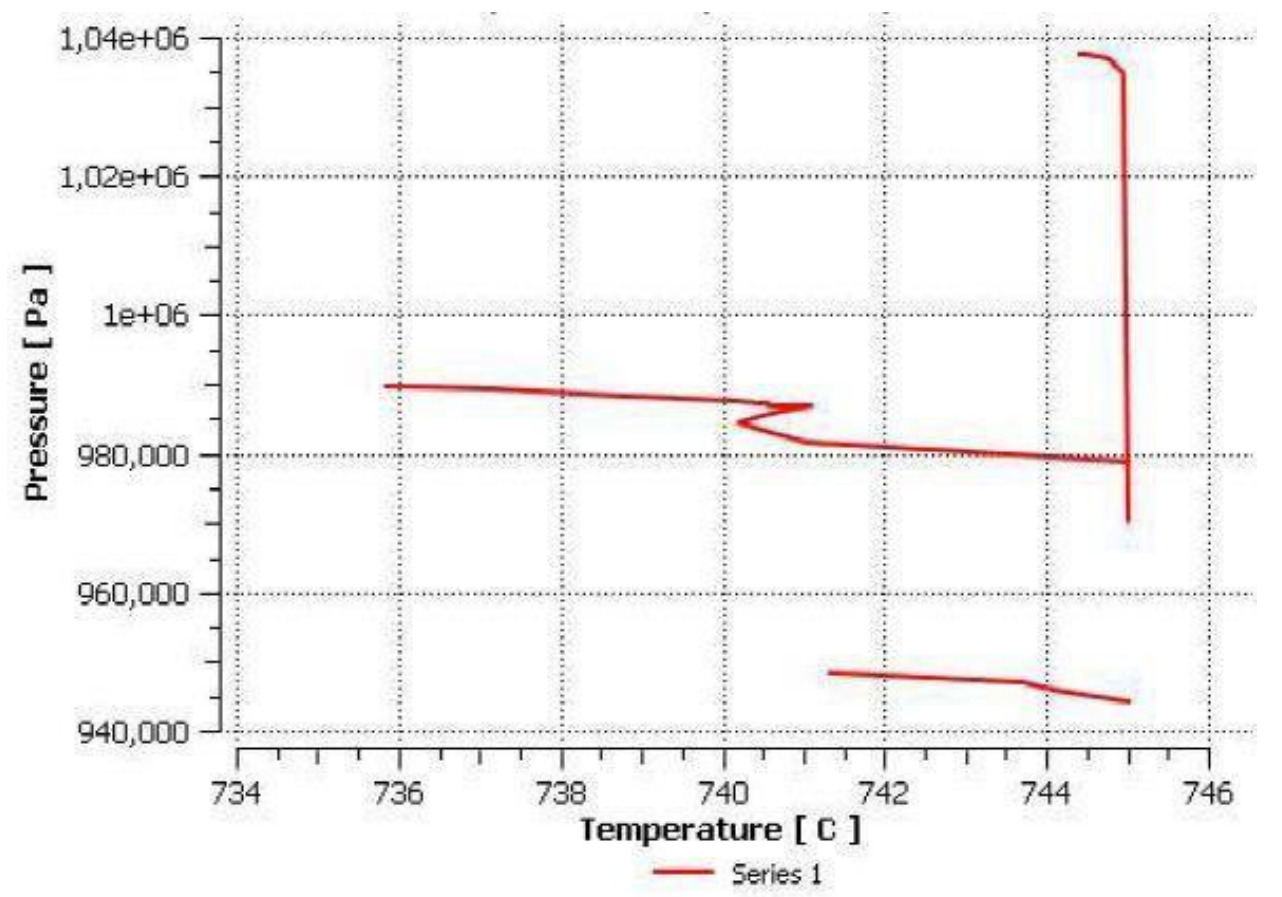

Fig.25 Pressure v/s Temperature graph on s-CO2 hot plate side

\section{CONCLUSION:}

- Channel number is complex in design of plats because PCHE channel geometries of both zigzag and S-shaped fins are same with those in the prototypic design.

- There are many factors taken into count in the design. Primarily, the number of zigzag and S- shaped fin channels on every plate must be designed to carry identical overlapping width, because of heat transfer area needed to be overlapped as much as possible to have required heat transfer performances.

- In addition to that, channels number per plate must be enough to remove the maldistribution of fluids. Also, the number of plates is desired to be large sufficiently to degrade the effect of heat removal of the test PCHE.

- Furthermore, the total number of channels is connected to the mass flow rate of the test PCHE, which is necessary in creating s- $\mathrm{CO} 2$ loop test facility. The mass flow rate on the s-CO2 side must be small sufficiently so that there can be a pump commercially accessible for this kind of high pressure system.

- The pump which needs to be installed in the STL must be magnetically enclosed gear pump to decrease the potential 
leakage of s-CO2 in the facility. In the contemporary design, both of zigzag and S-shaped fin channels contain 8 plates with a total of 16 plates stacked up to build the whole PCHE core.

- On every zigzag plate, there are 12 channels having total width of $51.41 \mathrm{~mm}$. This shows that in terms of the overlapping width the number taken into count of channels per plate meets need of design requirement.[1]

- Thus, the analytical results gained are quite enough in terms of our aim and future can be experimented and utilized for the use in the nuclear power system.

\section{FUTURE SCOPE:}

- Various diffusion bonding parameters must be studied considering importance of various factors which are bonding time, bonding atmosphere conditions, use of Ni-inter layers and PBHT, etc. They are to be studied for checking feasibility and adaptability of the compact heat exchanger

- The post-test destructive inspection had a burst test of a decommissioned PCHE made of Inconel 617 should be done. The testing process must be done as per ASME standards. There were two tests, each on different side of the PCHE. 1000 bar was achieved and maintained for 60 seconds on the straight-side channels, which can be practised to endure the hydrostatic pressure. Currently, estimate that MAWP for the PCHE is $4.5 \mathrm{MPa}$ at $800{ }^{\circ} \mathrm{C}$ and $25 \mathrm{MPa}$ at room temperature [1].

\section{REFERENCES:}

1. Compact Heat Exchanger Design and Testing for Advanced Reactors and Advanced Power Cycles, Brian Robinson (Federal POC), Matt Carlson (Technical POC)

2. ASME Code considerations for the compact heat exchanger by J. Nestell ,MPR Associates, Inc. and T.-L. Sham of Oak Ridge National Laboratory.

3. A review of Alloy $800 \mathrm{H}$ for application in the generation IV nuclear energy systems. 